\title{
RECONNAISSANCE LEVEL STUDY MISSISSIPPI STORM SURGE BARRIER
}

\author{
M. van Ledden ${ }^{1,3}$, A.J. Lansen², H.J. de Ridder ${ }^{3}$, B. Edge ${ }^{4}$
}

\begin{abstract}
This paper reports a reconnaissance level study of a storm surge barrier in the Mississippi River. Historical hurricanes have shown storm surge of several meters along the Mississippi River levees up to and upstream of New Orleans. Future changes due to sea level rise and subsidence will further increase the risk of flooding due to hurricane storm surge. A surge barrier downstream of New Orleans has been considered as an alternative to levee raise along the Mississippi River. Hydraulic computations show that the build-up of water behind the barrier due to the Mississippi River flow is (much) lower than the hurricane surge protruding up the river in the no-barrier situation. The barrier will probably eliminate the need to upgrade the system upstream of the barrier while providing the same level of hurricane risk reduction. A hybrid barrier (a combination of different gate types) with a primary swing gate for navigation (and flow) and secondary lift gates to accommodate for flow is a technically feasible alternative. The barrier remains open for almost the entire year and would only to be closed during severe tropical events (say once every 2 - 3 years). Several measures are included in the conceptual design to mitigate the navigation impact. The construction costs of the barrier are estimated at $\$ 1.6-2.6$ billion. It is recommended to compare the investment costs of a barrier including adjacent tie-ins to the existing HSDRRS to the costs of upgrading and maintaining the levee system throughout the city of New Orleans.
\end{abstract}

Keywords: surge reduction; storm surge barrier; Mississippi River, hurricanes

\section{INTRODUCTION}

The US Army Corps of Engineers has been responsible for delivering a 1\% perimeter Hurricane and Storm Damage Risk Reduction System (HSDRRS) after Katrina. The HSDRRS includes levees, flood gates, surge barriers and pump stations along Lake Borgne, Lake Pontchartrain at the East Bank and the Barataria Basin at the West Bank of the Mississippi River (Figure 1). This system has been designed to withstand hurricane surge and associated waves with a $1 \%$ probability of exceedance in any given year as authorized by Congress. Parts of this system have been completed or are under construction (USACE, 2007).

Historically New Orleans has suffered extensive damages from hurricanes. Hurricane Katrina raised the water level in the Mississippi River over 3.5 meters near downtown New Orleans. Its peak was just below the project design flood level in the Mississippi River. Future changes due to sea level rise and subsidence will increase hurricane surge on the Mississippi River. Raising the existing Mississippi River \& Tributary (MR\&T) levee system as part of the new Hurricane System Damage Risk Reduction System (HSDRRS) to maintain the 100-year risk reduction will probably be very costly, time consuming and will have great impacts on the densely populated area and the many port activities along both river banks. These challenges will be even larger if a higher level of risk reduction for the city of New Orleans would be considered (e.g. 500-year or even higher).

The challenges provide an opportunity for considering a storm surge barrier in the Mississippi River as an alternative to levee height increases in the highly urbanized area of downtown New Orleans. This barrier would only be closed during hurricanes and prevent the surge from entering the Mississippi River and would be open during non-hurricane conditions to allow navigation and the passage of river floods. The success of the well-known Maeslant Barrier in Rotterdam was the basis for considering a Storm Surge Barrier on the Mississippi River. Reference is made to Rijkswaterstaat (2000) for more technical details about the Maeslant Barrier. Construction of this barrier in the 60ft deep and 1000ft wide access channel to the Port of Rotterdam turned out to be more cost effective than raising the levee system throughout the entire city. Also, a shorter timeframe for construction and less urban and environmental impacts were positive aspects of this solution. The barrier was completed in 1996 and was successfully closed during storm conditions in 2007.

\footnotetext{
${ }_{1}^{1}$ Royal HaskoningDHV, George Hintzenweg 85, Rotterdam, The Netherlands, mathijs.van.ledden@rhdhv.com

2 Royal HaskoningDHV, Ho Chi Minh City, 236/26C Dien Bien Phu Street, Ward 17, Binh Thanh District, Vietnam

${ }^{3}$ Delft University of Technology, Stevinweg 1, PO Box 5048, 2600 GA Delft, The Netherlands

${ }^{4}$ North Carolina State University, Department of Civil, Construction, and Environmental Engineering, Raleigh, NC27965, United States
} 
The purpose of this study is to conduct reconnaissance level study of constructing a storm surge barrier in the Mississippi River to reduce risk along the MRL in lieu of raising the levees along the river. Specific objectives of this study are i) to identify technical challenges and opportunities of a storm surge barrier alternative, ii) to develop a conceptual design and cost estimate of a barrier alternative, and to iii) assess potential challenges with respect to environmental aspects such as navigation, real estate, operations and maintenance, reliability etc.

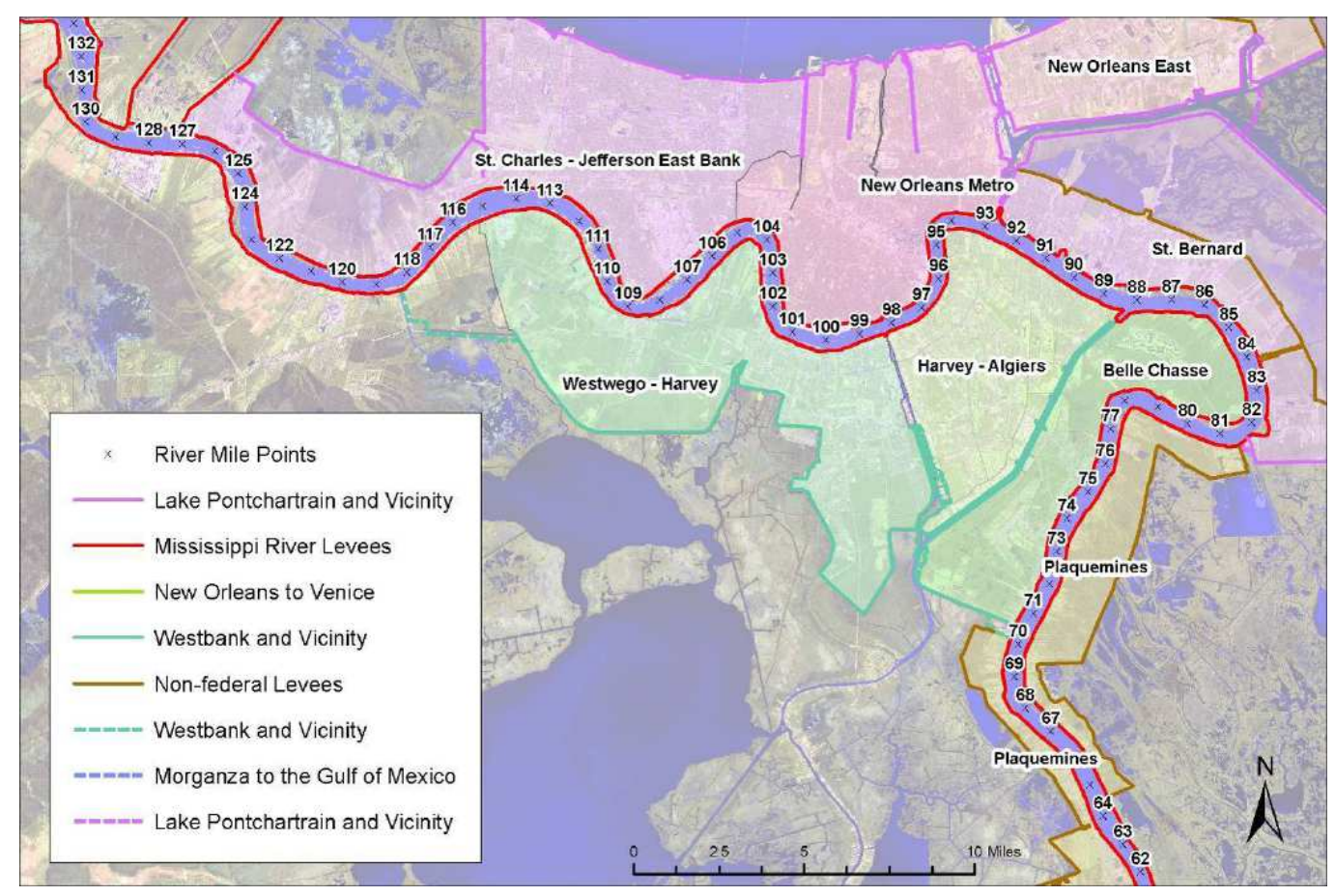

Figure 1. Greater New Orleans area with the Hurricane Storm and Damage Risk Reduction System.

\section{A STORM SURGE BARRIER IN THE MISSISSIPPI RIVER}

\section{Hurricane threat in the river}

The area of interest in this study along the Mississippi River is shown in Figure 1. Although the mouth of the river is about 100 river miles downstream of New Orleans, the hydrodynamic behavior of the Mississippi River in New Orleans is influenced by both the river discharge and the water levels in the Gulf of Mexico. A flood protection system (levees, floodwalls, structures) exists at both the East Bank and West Bank of the Mississippi River to protect the surrounding areas from river and coastal flooding. Historical observations and modeling of over 150 hurricane paths have shown that hurricanes generate substantial surge levels in the Mississippi River near New Orleans (see e.g. USACE, 2008). Figure 2 presents the surge level at Carrollton at River Mile 103 (see Figure 1 for location). The peak surge level reached 3.5 meters NAVD88 2004.65 during Katrina, whereas the mean water level is about $0.5-1$ meter between June and October. It is noted that the peak surge level during Hurricane Katrina is just below the river stages associated with the design river flow in the Lower Mississippi through New Orleans. 


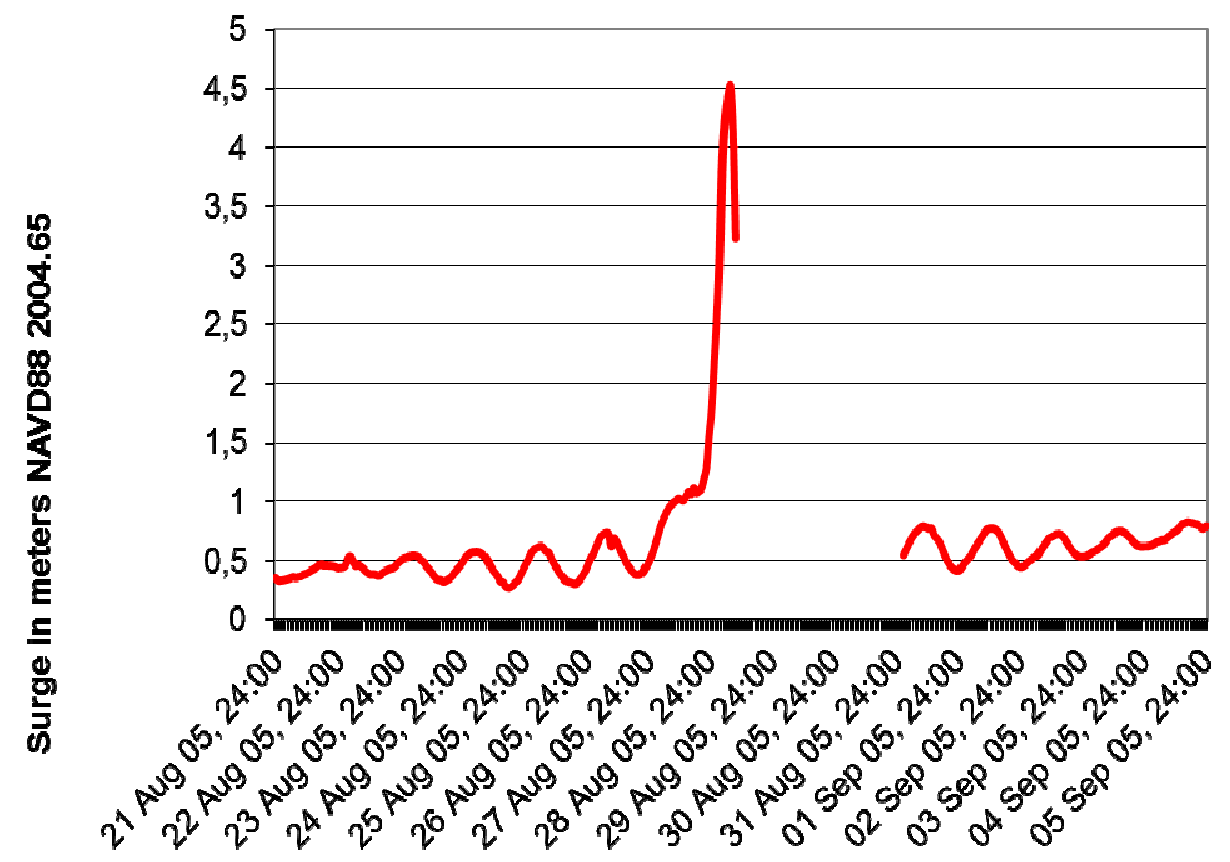

Figure 2. Surge level during Hurricane Katrina at Carrolton (River Mile 103, see figure 1).

Engineering analysis has shown that portions of the Mississippi River levees need to be upgraded to meet the $1 \%$ HSDRRS criteria. In the short-term, the river system in between RM70 - 80 at the West Bank shows elevation deficiencies. More substantial work is necessary to meet the $1 \%$ design conditions when future conditions (2060) are considered. Note that the levee upgrades need to be carried out in the densely populated area with high economic activity along the river. Therefore, the costs for construction will be higher than in more rural environment because of real estate costs and other relocation costs. Also, the process of implementing these upgrades could be very time consuming because of relocations, environmental impacts, acquisition of real estate, etc. Also, the impacts on other economic activities (such as the Port of New Orleans) could be another challenge for upgrading the levee system in the city.

\section{Surge reduction barrier}

The principle function of a barrier downstream of New Orleans would be to close off the Mississippi River during high storm surge for a short period of time and thereby lower the storm surge levels in the city of New Orleans. In this way, the need for raising the levee system upstream of the storm surge barrier from a hurricane protection point of view would be eliminated (Figure 3). Levees would still be necessary because of the river flood events. The barrier has to remain open during nonhurricane conditions to allow navigation and safely pass riverine flood events. Mississippi River is a very important navigation route with large shipping volumes. Also, river floods occur regularly and the barrier should not obstruct free river flow (and thereby worsen the river flood risk) during these events. 


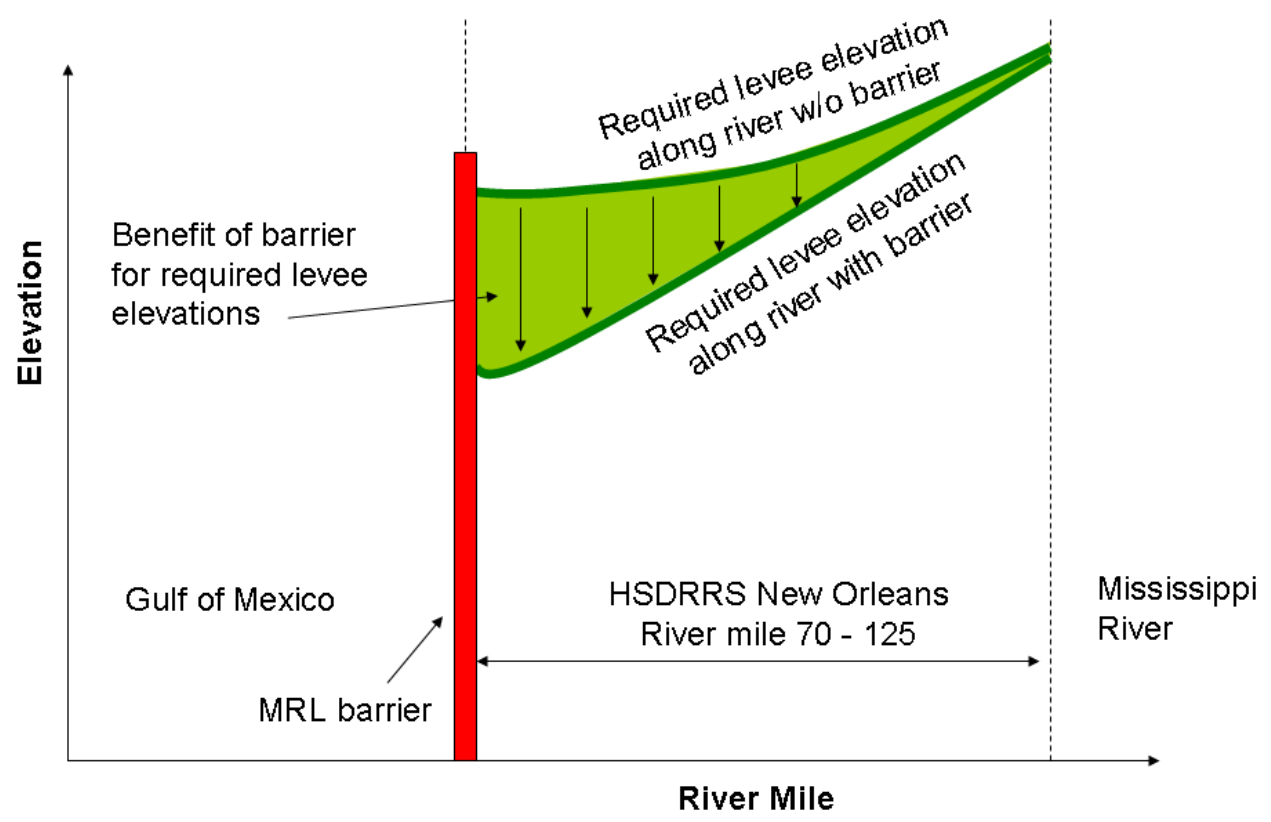

Figure 3. Conceptual diagram of the potential savings in required levee elevations due to a storm surge barrier.

The quantification of the reduction in surge level elevation is an important key to assess the effectiveness of a barrier solution. From a statistical point of view, the combined statistics of storm surge and river discharge determines the probability of occurrence of a water level in the Mississippi River. For an identical storm, a high discharge will result in higher water levels than a low discharge. Similarly, a higher water level will be produced with a stronger storm with the same discharge. Spatially, the water levels will be more dominated by the river discharge in the upstream portion of the river, whereas the hurricane surge will influence the resulting water levels more downstream on the Mississippi River.

Since a full statistical analysis was beyond the scope of this study, a simplified approach was followed to quantify effect of the barrier solution on the surge levels. First, the river discharge during the hurricane season (June to October) was analyzed and three different discharge levels have been established to cover the range (roughly $10 \%, 50 \%, 90 \%$ exceedance probability). Next, three individual storms from the 152 ADCIRC storm suite for South East Louisiana (Resio, 2007) have been selected which result in the $1 \%$ water level at Carrollton (RM103) for each of these river discharge situations. The table below presents the selected storm-discharge combinations which result in a $1 \%$ surge elevation of 4.9 meter NAVD88 2004.65 at Carrollton. Using these three different storm-discharge combinations, a one-dimensional hydraulic model has been applied to assess the effect of a barrier on the surge levels. The resulting surge level reduction due to the barrier is presented in Table 1 for different stations along the river. Figure 4 shows the temporal water level variation upstream and downstream of the barrier for these storm-discharge combinations. 

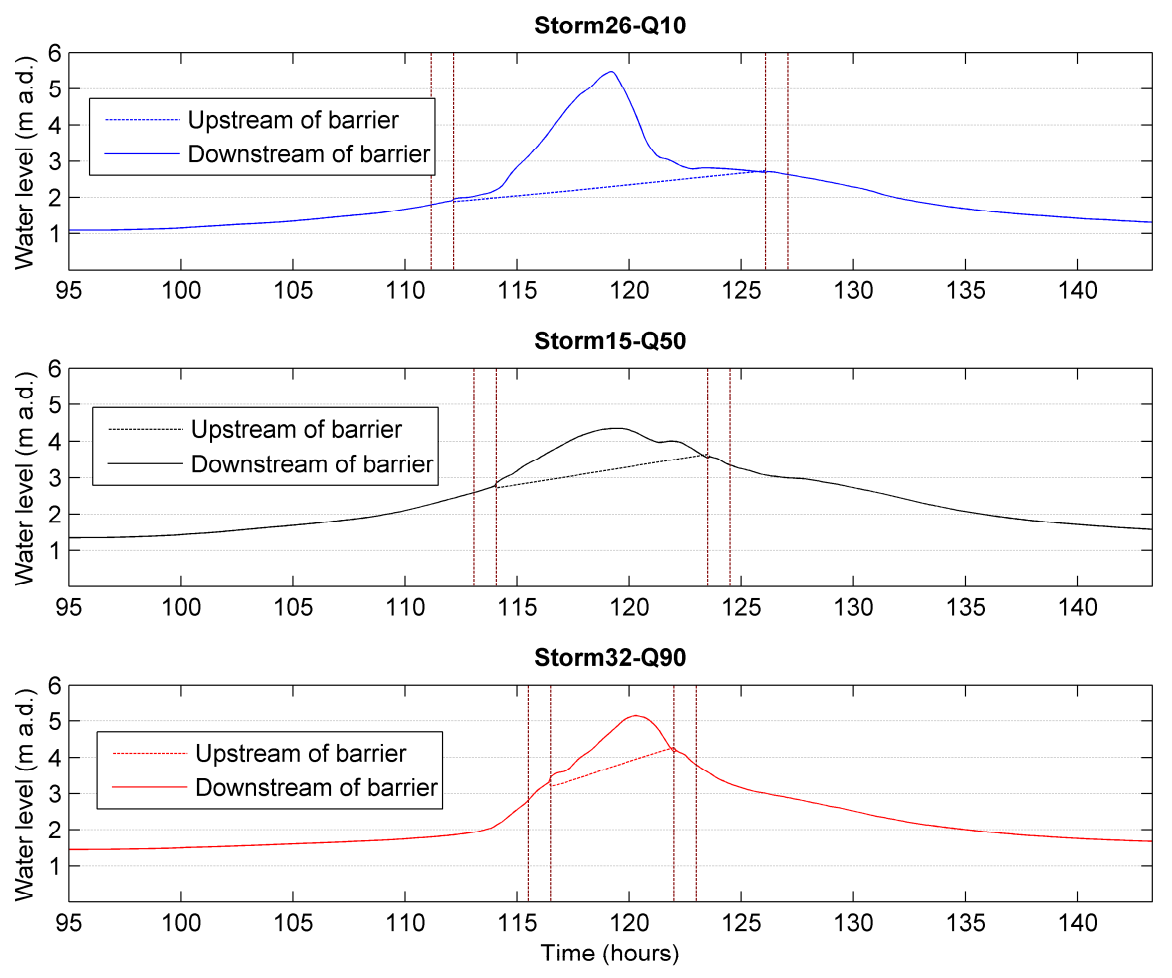

Figure 4. Water level variation during storm conditions upstream and downstream of the barrier for three storm-discharge combinations.

\begin{tabular}{|c|c|c|c|c|c|}
\hline \multicolumn{7}{|c|}{ Table 1. Surge level reduction in meters due to storm surge barrier operation } \\
\hline Station & $\begin{array}{c}\text { Algiers Lock } \\
\text { (RM88) }\end{array}$ & $\begin{array}{c}\text { IHNC Lock } \\
\text { (RM93) }\end{array}$ & $\begin{array}{c}\text { Carrollton } \\
\text { (RM103) }\end{array}$ & $\begin{array}{c}\text { Bonnet Carré } \\
\text { Spillway (RM127) }\end{array}$ & $\begin{array}{c}\text { Donaldsonville } \\
\text { (RM174) }\end{array}$ \\
\hline Storm 26- Q10 & 2.4 & 2.3 & 2.3 & 2.0 & 1.6 \\
Storm 15- Q50 & 0.7 & 0.7 & 0.7 & 0.7 & 0.7 \\
Storm 32- Q90 & 0.9 & 0.9 & 0.9 & 0.8 & 0.8 \\
\hline
\end{tabular}

From Table 1 it can be concluded that the effect of closing the Mississippi River during hurricane surge is in the order of $2-2.5$ meter for low river discharge and $0.5-1$ meter for higher discharges. The presented results clearly show that the barrier solution is most effective for low river discharges. If the discharge is larger, the water level behind the barrier will rise more quickly and the surge level reduction behind the barrier will be less. Several remarks are made:

- The relative small effect for higher discharges can be partly attributed to the design frequency. In the Rotterdam case, the reduction of the surge in the $1 \%$ situation by the storm surge barrier is "only" 0.5 meter, whereas the effect is 1.5 meter for the design condition (1/10,000 year).

- The effect of future conditions has not been investigated. Relative sea level rise will raise the surge levels downstream. A higher downstream peak surge level will have similar consequences as considering a lower frequency (see also previous bullet).

Despite these limitations, the surge level reduction due to the barrier presented in Table 1 indicates that the levee upgrades which are necessary in the short-term between RM70 - 80 at the West Bank would be completely eliminated. Also, the required upgrade of the levee system upstream of New Orleans could be eliminated, or at least significantly minimized, by the storm surge barrier. It is strongly recommended to quantify the costs of these upgrades and compare this with the costs of the barrier solution to see which alternative is more cost effective. Especially for the long-term, it is envisioned that this barrier could be a competitive alternative to raising the levee system if costs and other impacts are being compared. 


\section{CONCEPTUAL DESIGN OF THE BARRIER}

\section{Boundary conditions and requirements}

A thorough understanding of the boundary conditions is important to assess which barrier options are feasible. These boundary conditions are listed in Table 2 including the source of information. Most hydraulic information has been retrieved from studies performed by the US Army Corps of Engineers (see USACE, 2007; 2008). The engineering geological characteristics including the subsoil geology for an area encountered close to the project location have thoroughly been discussed by Heinrich (2005) and have been applied in this study.

\begin{tabular}{|c|c|c|c|}
\hline Discipline & Item & Condition & Source \\
\hline Geotechnical & $\begin{array}{c}1 \% \text { Design surge } \\
1 \% \text { Storm duration } \\
1 \% \text { Design head } \\
\text { River discharge }(10-50-90 \%) \\
\text { during hurricane season } \\
1 \% \text { waves }\left(\mathrm{H}_{\mathrm{s}}, \mathrm{T}_{\mathrm{p}}\right) \\
1 \% \text { Wind speed } \\
\text { Peak stage at river flood } \\
\text { Bulk unit weight } \\
\text { Undrained shear strength }\end{array}$ & $\begin{array}{c}+5.5 \mathrm{~m} \text { NAVD88 } \\
6-12 \text { hours } \\
3.5 \mathrm{~m} \\
5000,8300,13400 \mathrm{~m}^{3} / \mathrm{s} \\
1 \mathrm{~m}, 3 \mathrm{~s} \\
34 \mathrm{~m} / \mathrm{s} \\
+3.2 \mathrm{~m} \mathrm{NAVD88} \\
17,000 \mathrm{~N} / \mathrm{m}^{3} \\
\text { Stepwise linear profile }\end{array}$ & $\begin{array}{c}\text { ADCIRC and statistical analysis (see } \\
\text { USACE, 2008) } \\
\text { 1D calculations with SOBEK } \\
\text { 1D calculations with SOBEK } \\
\text { 1976 - } 2002 \text { data set of Lower } \\
\text { Mississippi discharge } \\
\text { Estimate with Bretschneider } \\
\text { Design report (see USACE, 2007) } \\
\text { Q-h relationship at location of barrier } \\
\text { Based on local data from USACE } \\
\text { Based on data from USACE }\end{array}$ \\
\hline
\end{tabular}

\section{Functional requirements}

Also, a list of functional requirements has been compiled for this barrier. These requirements are summarized in Table 3.

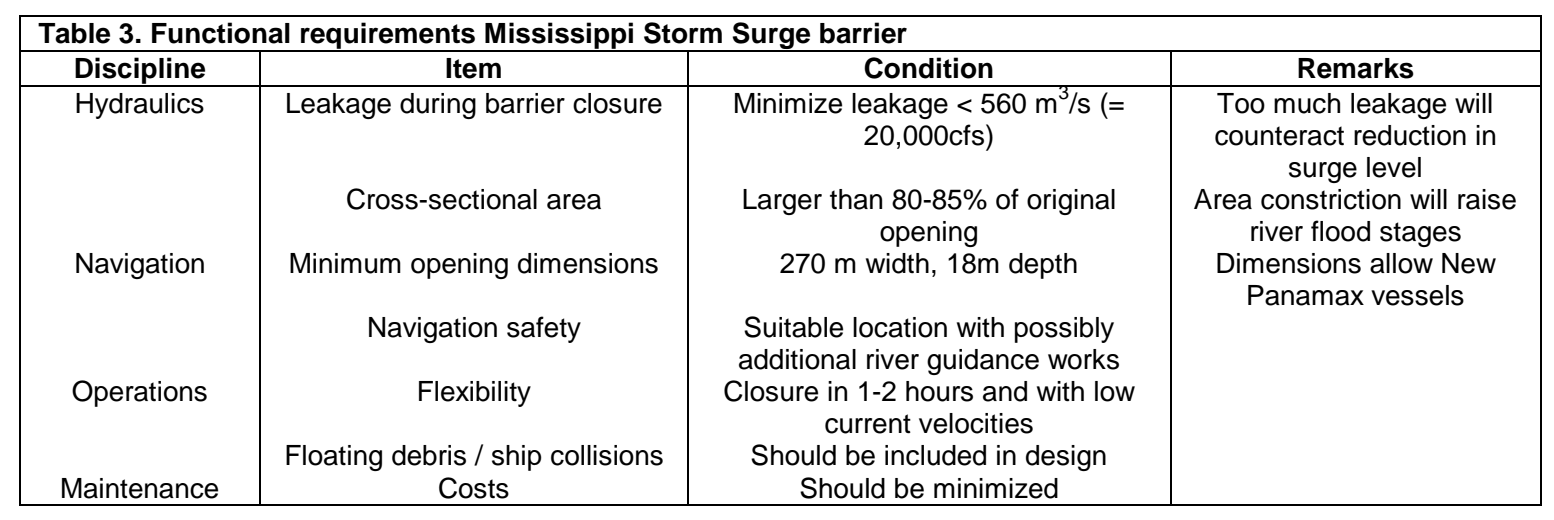

\section{Location barrier}

The search area for a barrier location in this study is taken in between RM70 (tie-in of the West Bank levee system) and RM81 (tie-in of the East Bank levee system), see figure 1. The reason for this is that the shortest line of defense of the overall system will be achieved. A location more upstream or downstream is possible, but will result in additional length of the flood defense system. Note that independent of the exact location in between RM70 and RM81 - the Mississippi River levees from the barrier towards the West Bank and East Bank tie-ins need to be upgraded in this entire barrier concept to provide the level of risk reduction from a system's point of view.

River Mile 71.3 is found to be the preferred location of a storm surge barrier in the Mississippi River (see figure 1). The primary argument is that the cross section is fairly rectangular. This is beneficial in that not much dredging is needed, the existing natural profile is used as much as possible and the construction depth of the sill could be limited. Another reason for choosing this location is that the approaching vessels going downstream and making the sharp turn in the river bend around RM 7879 (English Turn) have view on the structure from a good distance which will optimize navigation safety. No geotechnical or hydraulic considerations are found which severely overweigh these arguments. The selected cross-section at RM71.3 has an average depth of about $22.5 \mathrm{~m}$. For design purposes, the cross section is schematized as a straight rectangle measuring $800 \mathrm{~m}$ wide. 


\section{Barrier type}

Different barrier type options have been reviewed (see also PIANC, 2005). It was found that selecting different barrier types for the main (navigation) opening and for the opening to allow river flow (Table 4) is most feasible. For the Mississippi barrier a hybrid barrier with a primary swing gate for navigation (and flow) and secondary lift gates to accommodate for flow have been selected. The primary gate size has an $18 \mathrm{~m}$ deep and $275 \mathrm{~m}$ wide opening to allow shallow and deep draft navigation. The hybrid barrier concept is favorable since forces are guided towards the subsoil using several piers, which makes foundation requirements less challenging and costly. Given the weak soil conditions, a barrier type solution as was applied in Rotterdam is not deemed feasible. This concept also offers a solution to the negative effects associated with sedimentation at the sill of the gates.

Innovative aspects are that the primary gate will be pushed in closed and open position by the reversing currents. Also, the sluice gates within the swing gate are open during opening and closing of the swing gate to reduce the hydraulic forces. Closure will commence before the onset of tropical force wind speeds are expected. Closing and opening time is expected to be 1 hour. The total closure time will be approximately 6 to 12 hours.

\section{Barrier dimensions}

A conceptual design has been made of the hybrid barrier (Figure 5). The swing gate has a "wet profile' 274.3 meter (width) and 18.3 meter depth. The large gate opening is the minimal navigation width. The sill level is kept as high as possible to minimize design loads on the main gate. Five 'side gates' are considered of 85 meter width each. Experience from reference projects shows that using gates with a width of 75 to 100 meters provides the most cost-effective solution for conventional barrier designs. The five side channels with the lifting gates have a 'wet profile' of $85.3 \mathrm{~m}$ wide and $-21.9 \mathrm{~m}$ deep.

For the lifting gates, the sill height is therefore lower than the swing gate because i) The depth and wet profile reduction are minimized to increase the total cross section available for discharge, and ii) the influence of the barrier on the sediment transport has to be minimized. Bed load transport is located in the deepest part of the river. Hence, having the sill of the lifting gates lower than the large swing gate has a large benefit. Sedimentation of the sill can be easily mitigated by a yearly test closure of the gates. Also, the probability of sedimentation of the main gate is reduced significantly. As a result the restriction of the existing 'wet profile' (including piers) is $20.2 \%$ (average depth reduces with $8.9 \%$ and width with $12.4 \%$ ). With this constriction, the effect on the river stages during peak river flow upstream of the barrier will be very small.

The top of the gates are designed at $0.6 \mathrm{~m}$ above storm surge level +5.5 m NAVD to reduce wave overtopping (leakage) and to keep the gates visible during closure. The main gate is therefore 24 meter high and 280 meter long. Side gates are 28 meter high and 86 meter long. 


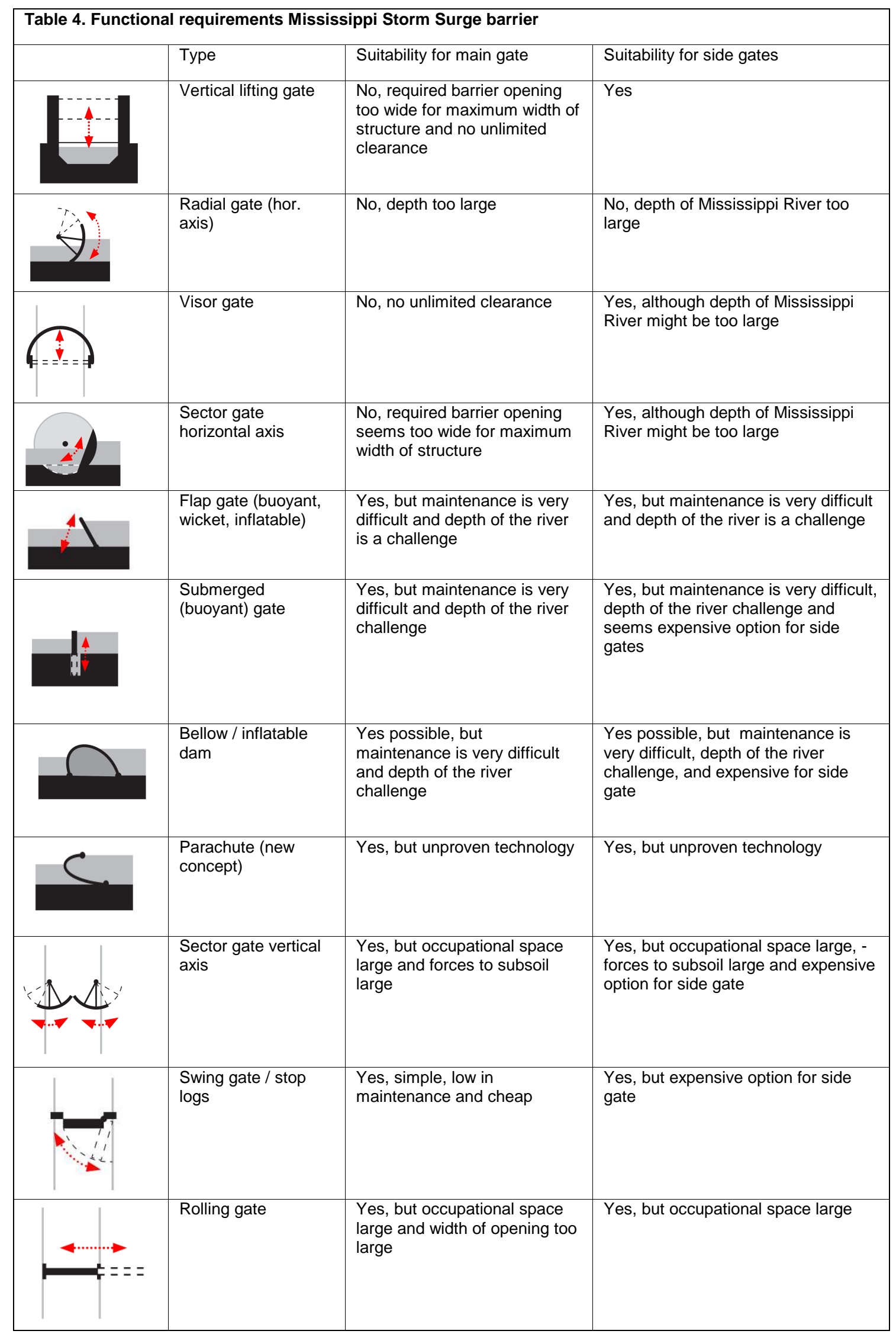




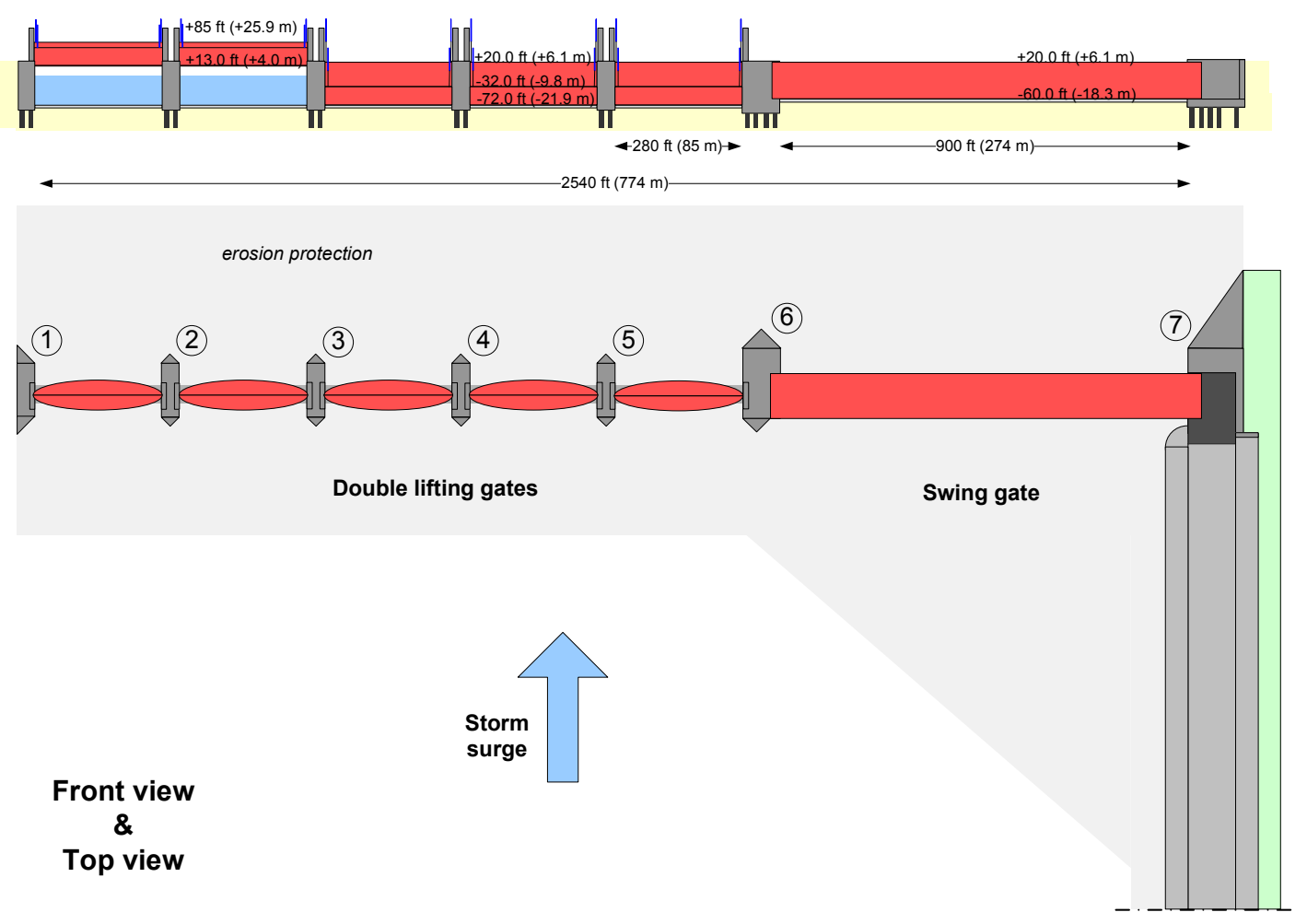

Figure 5. Dimensions of the hybrid barrier design for the Mississippi Barrier.

\section{IMPACTS OF THE BARRIER}

\section{Environmental impacts}

The construction of the storm surge barrier will have an impact on the environment. It is noted that the environmental impacts from the barrier need to be considered in view of the alternative measure of risk reduction, viz. raising the levees and floodwalls in New Orleans. By identifying the impacts, potential solutions can be sought which could limit the environmental impact. Even solutions can be found which might be beneficial for the environment.

The impact on the environment is discussed for a number of items:

Operational impact on eco-system: The barrier is operated only once in a few years and hence there will be limited impact to the eco-system. The maintenance of the barrier will require much lubrication and painting, and as such will have a negative effect on the immediate surroundings. Effects are estimated to be local. Also, selection of construction material can mitigate much of the negative environment impact due to the operation of the structure.

Construction impact on eco-system: The area which is needed for construction of the barrier mainly consists of the inner part of the Mississippi River. Additional space might be required at either end for maintenance buildings, spare parts storage, working harbor, etc. During construction, the area of impact would be much larger. Especially for construction of the main piers, a polder might have to be created outside the Mississippi River banks which can be used as a dry dock. Careful site selection might mitigate potential impact to the environment. All steel parts can be constructed elsewhere.

Environmental "footprint" of materials (pollutions, energy consumption): During construction, material will be brought in from various places. Large quantities of rock, concrete are required. Given the dimensions of the project, it is likely that the environmental footprint will have the most significant environmental impact. 
Opportunity for win-win in combining barrier with river diversions: River diversions have been built in the past decades on the Mississippi River. A river diversion in close proximity of the barrier is the Caernarvon Diversion with a maximum discharge of about $226 \mathrm{~m}^{3} / \mathrm{s}(=8,000 \mathrm{cfs})$. Recently, it has been realized that large river diversions (e.g. $20-40 \%$ of the Mississippi discharge and its sediments) are probably necessary to have a substantial impact on the wetland restoration. During discussions about this barrier for the Mississippi River, the idea was raised to combine this barrier with a river diversion and hereby create a win-win situation for both risk reduction and coastal restoration.

\section{Navigational impacts}

The hybrid design of the surge barrier provides the option to construct the barrier in several phases. Doing so, the total width of the Mississippi River can be used to change fairway during the construction period. The depth of the river is sufficient over the total cross section at the location of interest (RM 71.3) so that navigation can take place over a large portion of the cross section. Therefore, hindrance for navigation is limited to a change of fairway during construction.

After construction of the barrier, the fairway will have been restricted and additional guidance systems have to be installed. The local navigation depth is designed to New Panamax dimensions. The width at the barrier is designed taking into account further increase in vessel dimensions. This allows for safe passage of navigation for a new generation of ships. In the design, an opening of 300 meters has been assumed, which is wider than the navigable cross section at the two bridges in New Orleans. Maintenance of the swing gate takes place outside of the fairway of the river. No hindrance is expected therefore. For the lift gates, no hindrance is foreseen either.

\section{Other impacts}

By constructing a storm surge barrier in the Mississippi River, the total length of flood defense that needs to be maintained and operated to withstand hurricane conditions, is reduced significantly. From a system's approach, it is beneficial to reduce the length of a flood defense so that the number of components (levee sections, gates, etc.) is small. Design requirements for the levees upstream of the barrier will also be far less if a barrier is in place downstream. These aspects are all very beneficial to reduce the overall flood risk of the system. A follow-up study is recommended to quantify the reduction in risk at a system scale and comparing the levee raise alternative to a barrier alternative.

\section{BARRIER COSTS FOR CONSTRUCTION AND OPERATION}

\section{Construction costs}

A limited number of storm surge barriers have been built around the world. In addition, storm surge barriers are tailor made to local situations: construction techniques, access to construction material, labor cost and so forth will vary per project and per country. This means that no generally accepted cost estimate method, based on many examples, exists. A construction cost estimate can also be based on the actual design of a barrier. Knowing the dimensions in combination with construction plan, the individual cost components can be identified and quantified. In an early stage of a project however, this will be difficult to achieve. All components of a project need to be addressed to make a reliable cost estimate. For instance, customized equipment might be needed for which it is hard to make a cost estimate at an early stage.

For this feasibility study an approach has been chosen which considers the actual construction costs of several storm surge barriers in various countries around the world. The actual building costs and various physical parameters (height, length and head difference during design conditions) have been gathered for a number of storm surge barriers. These costs have been translated to a price level of 2010 and are listed in Table 4. Next, it has been assumed that the construction costs are proportional to the width, height and also the design head difference. This results in an average unit price equivalent to 31,000 US $\$$ per $\mathrm{m}^{3}$. 


\begin{tabular}{|c|c|c|c|c|c|c|c|}
\hline Name & Type & Year & $\begin{array}{c}\text { Width } \\
\text { (m) }\end{array}$ & $\begin{array}{l}\text { Height } \\
\text { (m) }\end{array}$ & $\begin{array}{c}\text { Head } \\
\text { (m) }\end{array}$ & $\begin{array}{c}\text { Construction } \\
\text { costs } 2010 \\
\text { (x } 10^{6} \text { US } \$ \text { ) }\end{array}$ & $\begin{array}{c}\text { Costs per } \\
\text { m3 }\left(\times 10^{3}\right. \\
\text { US } \$)\end{array}$ \\
\hline Ems Barrier, Germany & Sector gate & 1980 & 360 & 8.5 & 3.8 & 508 & 44 \\
\hline Thames Barrier, UK & Sector & 1980 & 530 & 17 & 7.2 & 2000 & 31 \\
\hline Eastern Scheldt Barrier, NL & Lifting gates & 1986 & 2400 & 14 & 5 & 5549 & 33 \\
\hline Maeslant Barrier, NL & Floating gate & 1991 & 360 & 22 & 5 & 905 & 23 \\
\hline Hartel Barrier, NL & Lifting gates & 1991 & 170 & 9,3 & 5,5 & 197 & 23 \\
\hline Ramspol, NL & Bellow barrier & 1996 & 240 & 8.2 & 4.4 & 182 & 21 \\
\hline Seabrook barrier, USA & Sector gates & 2010 & 130 & 8 & 4 & 158 & 38 \\
\hline $\begin{array}{c}\text { IHNC barrier, USA } \\
\text { Average }\end{array}$ & Sector gates & 2010 & 250 & 12 & 6 & 715 & $\begin{array}{l}40 \\
31\end{array}$ \\
\hline
\end{tabular}

Using the dimensions of the storm surge barrier in the Mississippi River and the average cost estimate, a capital cost investment of 2.1 billion US\$ is found. For the eight storm surge barriers listed in Table 4, a standard deviation of $\$ 8,000 / \mathrm{m}^{3}$ is found. A lower and upper bound of the cost estimate has been calculated with $\$ 23,000 / \mathrm{m}^{3}(=31,000-8,000)$ and $\$ 39,000 / \mathrm{m}^{3}(=31,000+8,000)$, respectively. Capital costs of the construction of a storm surge barrier in the Mississippi River are estimated to be within the range of $\$ 1.6$ billion to $\$ 2.6$ billion. It is noted that the barrier option proposed for the Mississippi, a swing gate, is fairly simple in design and construction compared to other solutions in this table. Local circumstances are difficult but not much different from conditions at locations around the world where other barriers have been built. Hence, construction costs close to lower bound of the 1.6 - 2.6 billion US \$ range may be a good first order estimate for the Mississippi barrier.

\section{Operation \& Maintenance costs}

Without being complete, important operation and maintenance costs of the barrier will be i) maintenance of the movable parts of the structure, ii) painting of the structure, iii) personnel, iv) measurement network, v) inspection of the various parts including submerged parts. The present design of the Mississippi barrier should be of low maintenance due to the following aspects. First, the maintenance of the swing gate can be done in a dry dock. This makes maintenance fairly easy. Second, the lifting gates are low in maintenance and easily accessible by an auxiliary bridge. Third, no movable parts are located under water which need under water maintenance.

Nevertheless, operation and maintenance costs of a large barrier will be substantial. From maintenance numbers of three other barriers in the world (Thames Barrier, Maeslant barrier, Eastern Scheldt barrier), it has been estimated that these costs are $0.5 \%$ of the construction costs. With the construction costs being $\$ 1.6$ billion - $\$ 2.6$ billion, operation and maintenance costs are estimated at $\$ 8$ - \$13 million per year for the Mississippi surge barrier.

\section{CONCLUSIONS AND RECOMMENDATIONS}

\section{Conclusions}

Preliminary hydraulic analysis has shown that a barrier solution near the downstream end of the HSDRRS (River Mile (RM) 70-80) will reduce the required flood defense design elevations upstream of the barrier substantially for the same level of risk reduction. First results show that the barrier will reduce the required $1 \%$ design elevations with $0.5-2.5$ meter in the river just upstream of the barrier. The barrier solution can be an opportunity to eliminate/reduce substantial work to the flood defense system (levees, floodwalls, locks, gates) throughout the city of New Orleans considering the reduction of the $1 \%$ surge levels due to a barrier, especially if the 2060 conditions are considered.

The design and construction of a storm surge barrier to withstand and counteract hurricane storm surge in the Mississippi River is technically feasible. No technical showstoppers have been identified which would make the barrier design technically impossible or extremely costly. The preferred location of the Mississippi River barrier is at RM 71.3. This location is in between the HSDRRS tie-in at the East Bank near Caernarvon (RM81) and the HSDRRS tie-in at the West Bank near Oakville (RM70). The proposed design of the storm surge barrier consists of a primary swing gate for navigation (and flow) and secondary lift gates to accommodate for flow. This hybrid storm surge barrier concept is considered to be the best alternative for the Mississippi situation from a technical point of view. 
Navigation is considered to be the key issue to be resolved for a successful barrier project. The navigational impact is mitigated in the presented design by 1) selecting a location in a straight section of the Mississippi River, awareness, visibility and navigational safety has been optimized, 2) proposing phased construction of the primary and secondary gates which limits hindrance during construction, and 3 ) keeping a large total flow opening to minimize the effects on flow velocities. Environmental impacts will be mainly a result of the large footprint of the barrier and the large amount of construction material needed.

The construction costs are estimated at $\$ 1.6-2.6$ billion. Operation and maintenance (O\&M) costs are estimated at $\$ 8$ - $\$ 13$ million per year. The basis for determining construction and O\&M costs were other storm surge barriers in the world. It is expected that the costs of a barrier to provide a higher level of protection (e.g. 500-year) will only be slightly higher however offering a significant higher level of protection.

\section{Recommendations}

The scope and impact of this project requires a risk and system based approach for a thorough cost benefit analysis. The levee raise alternative should be balanced to the storm surge barrier alternative. This should be done for both the present and the future conditions. Also, a higher level of risk reduction for the Greater New Orleans area could be considered. Several aspects such as environmental procedures, navigation, port activities, environmental impacts etc. need to be taken into account in this analysis as well.

The challenge for this barrier will be a design that guarantees a reliable operation procedure during hurricane events. The operation is challenging because the hydraulic interaction of hurricane storm surge and river discharge is complex. Furthermore, the effects of each hurricane are different, uncertain and difficult to predict. The presented design therefore consists of a simple barrier concept in which nature itself helps to close and open the main gate. Short closure times have been built into the design to maximize the reliability. It is recommended to pay strong attention to this aspect in a next phase.

\section{ACKNOWLEDGEMENTS}

USACE Task Force Hope has commissioned this study in the framework of implementing the $1 \%$ Hurricane Storm Damage Risk Reduction System after Katrina. The management of Task Force Hope is highly appreciated for its support and leadership to investigate alternative measures for risk reduction of the Greater New Orleans Area. Also, the enthusiastic cooperation within the team of Royal Haskoning DHV for this project has been inspiring. Thanks to all team members for their input and support during this study.

\section{REFERENCES}

Heinrich, P.V., 2005, "Louisiana Geological Survey December 2005, Review of the Engineering Geology of St. Bernard Parish, Louisiana.” NewsInsights, www.lgs.lsu.edu

PIANC, 2005. Design of Movable Weirs and Storm Surge Barriers, PIANC InCom WG26.

Resio, D.T., 2007. White Paper, Estimating Hurricane Inundation Probabilities. U.S. Army Corps of Engineers, ERDC-CHL, 2007.

Rijkswaterstaat, 2000. Basisdocumentatie Maeslantkering 1 \& 2 (Maeslant barrier 'as-built report'), 2000, Rijkswaterstaat; Ministry of Transport, Public Works and Water Management, The Netherlands.

USACE, 2007. Elevations for design of hurricane protection levees and structures, Lake Pontchartrain, Louisana and vicinity hurricane protection project, west bank and vicinity. Draft report, Final report, Prepared by New Orleans District, 15 October 2007.

USACE, 2008. 1\% levee elevations assessment Mississippi River levees Hurricane Storm and Risk Damage Reduction System New Orleans. Final Draft Report 27 November 2008. 